\title{
Simulation Analysis and Optimization of Rolling Process of Steel Rim
}

\author{
Wenhua Lv¹, Mao Pang1* ${ }^{*}$, Shunping Li ${ }^{2}$, Miaolong Cao ${ }^{1}$ \\ ${ }^{1}$ School of Mechanical and Energy Engineering, Zhejiang University of Science and Technology, Hangzhou, China \\ ${ }^{2}$ Zhejiang Jingu Company Limited, Hangzhou, China \\ Email: 221801852067@zust.edu.cn, ^Palmy@126.com
}

How to cite this paper: Lv, W.H., Pang, M., Li, S.P. and Cao, M.L. (2021) Simulation Analysis and Optimization of Rolling Process of Steel Rim. World Journal of Mechanics, 11, 34-51.

https://doi.org/10.4236/wjm.2021.113004

Received: February 1, 2021

Accepted: March 23, 2021

Published: March 26, 2021

Copyright (c) 2021 by author(s) and Scientific Research Publishing Inc. This work is licensed under the Creative Commons Attribution International License (CC BY 4.0).

http://creativecommons.org/licenses/by/4.0/

\section{(c) (i) Open Access}

\begin{abstract}
In order to solve the problems of rolling forming accuracy and fillet thinning of alloy steel rim, a three-dimensional model of three pass rolling process was established, and the influence of different process parameters on forming quality was analyzed by using the finite element software, and the optimal process parameter combination was obtained. On this basis, the simulation results of wheel rim stress and strain for each pass rolling are analyzed, and the particle tracking technology is introduced to analyze the variation rule of stress in each incremental step. Finally, the simulation and experimental results show that the simulation thickness is basically consistent with the actual thickness, which improves the accuracy of rim rolling forming, and further verifies the correctness of rolling process simulation.
\end{abstract}

\section{Keywords}

Roll Forming, Parameter Optimization, Simulation Analysis, Thickness

Verification

\section{Introduction}

With the acceleration of automobile lightweight process, alloy steel has been widely used in the production of automobile parts [1]. As the wheel hub is an important part of automobile driving, alloy steel for rim production can greatly reduce the mass of the wheel hub and improve vehicle driving performance [2]. However, due to the high strength and stiffness of alloy steel, the complex rolling process of wheel rim, the difficulty in controlling process parameters, high requirements on forming accuracy and thinning amount, and relatively difficult theoretical analysis. In the process of production and processing, enterprises mainly carry out experiments through "trial and error method", resulting in 
high production cost and long design cycle, which is not conducive to the development of new products.

With the maturity of finite element numerical simulation technology, through the rim rolling machining simulation, and according to the simulation results to analyze the deformation characteristics, it can improve the product design efficiency and forming quality. Deng, R., et al. [3] established the rim rolling simulation model, used the side guide wheel connecting spring to compress the blank, and optimized the simulation results to improve the engineering applicability. Wang H.L., Li Y.H., et al. [4] [5] established the finite element model of rim rolling forming, and focused on the influence of boundary conditions on the simulation results. At the same time, the metal flow and stress-strain distribution in the contact deformation zone are analyzed. Li D.Y., et al. [6] carried out simulation analysis on the roll bending process of U-beam, and optimized the roll diameter through orthogonal experiment. Tao H.W., Liu Z.W., et al. [7] [8] used numerical simulation technology to study the influence of material characteristics and roller speed on forming quality, and verified the accuracy of the analysis results through experiments. Based on the actual rolling process of the rim, the new modeling method and contact principle are determined. The influence of rolling speed and lateral force on the forming quality is considered in the parameter optimization, and the particle tracking technology is introduced to study the stress change state of the rim in different processing periods. Finally, compared with the thickness of the workpiece in the experimental production, the feasibility of the simulation is verified, which provides theoretical support for the enterprise rim manufacturing.

\section{Deformation Mechanism of Rim Rolling Material}

During the multi-step rolling process of automobile rim, the blank undergoes elastic and plastic deformation, and is formed into the final workpiece with the loading movement of the roller. The elasto-plastic deformation process is accompanied by a high degree of nonlinearity, and structural nonlinearity has always been a difficult point in the finite element analysis process. The incremental method is used to deal with the nonlinear problem, and the evolution history of stress and strain during the loading process can be obtained, and the solution accuracy is high, Good stability [9].

\subsection{Nonlinear Relationship of Rim Elastic-Plastic Finite Element Method}

There are many reasons for the non-linear problem of the blank, which can be divided into three main types: 1) The rim is geometrically nonlinear. The rim material undergoes a large deformation under the action of external load, which causes a large change in the force of the structure system. As the load continues to increase, the unit coordinates and structural rigidity in the workpiece change, causing the unit body to produce translation, torsion, elongation and compres- 
sion deformation cause changes in geometric shapes, resulting in a nonlinear response of the structure, that is, the force-displacement relationship is no longer proportional. When analyzing the linear response problem, the small deformation of the workpiece geometry is ignored. The linear relationship can be used to express the relationship between deformation and displacement. However, in the nonlinear response, the workpiece geometry deforms greatly, and the linear relationship is no longer applicable. Through continuous iteration, it can obtain a convergent solution. 2) Non-linear rim material. In the process of the large strain of the blank, the stress-strain of the material no longer conforms to Hooke's law, resulting in a complex nonlinear relationship. The influencing factors include (loading history, loading time, ambient temperature, etc.). 3) The boundary conditions of the rim are nonlinear. During the forming process of the blank, the contact area with the mold has been changing. With the continuous influence of load, material, constraints and other factors, it is difficult to perform linear analysis on the contact surface. At the same time, friction will also occur in the contact area, and the friction types are all Non-linear, its change process is more complicated, and the superposition of various factors makes the convergence of the contact area more difficult.

Therefore, it is necessary to numerically integrate the basic equation of infinitesimal increment form within the loading step time, and linearize the basic equation, so that the rim elastic-plastic nonlinear problem is simplified into a series of linear problems.

\subsection{Elastic-Plastic Finite Element Constitutive Equation of Wheel Rim}

The essence of rim elastoplastic constitutive relationship is the stress-strain relationship of the blank, the elastoplastic constitutive equation is calculated by the Von-Mises yield criterion. The yield stress is expressed by and the Von-Mises yield function is as follows

$$
f=J_{2}^{\prime}\left(\sigma_{i j}\right)-\frac{1}{3} \overline{\sigma^{2}}=\frac{1}{2} \sigma_{i j}^{\prime} \sigma_{i j}^{\prime}-\frac{1}{3} \overline{\sigma^{2}}=0
$$

The total strain increment is the sum of elastic strain increment and plastic strain increment. The calculation formula is as follows:

$$
d \varepsilon_{i j}=d \varepsilon_{i j}^{e}+d \varepsilon_{i j}^{p}
$$

where, $d \varepsilon_{i j}$ is the total strain increment, $d \varepsilon_{i j}^{e}$ is the elastic strain increment, and $d \varepsilon_{i j}^{e}$ is the plastic strain increment.

The elastic stress conforms to Hooke's law. The calculation formula is as follows:

$$
\begin{gathered}
d \sigma_{i j}=D d \varepsilon_{i j}^{e} \\
d \sigma_{i j}=D\left(d \varepsilon_{i j}-d \varepsilon_{i j}^{p}\right)
\end{gathered}
$$

where, $D$ is the elastic stress-strain relationship matrix, which is determined by 
Young's modulus and Poisson's ratio.

The relationship between yield stress, plastic strain and work hardening coefficient is as follows:

$$
H^{\prime}=\frac{\partial \bar{\sigma}}{\partial \overline{\varepsilon^{P}}}
$$

The relationship between plastic strain increment and stress state under the relevant flow criterion is as follows:

$$
d \varepsilon_{i j}^{p}=d \lambda \frac{\partial f}{\partial \sigma_{i j}}
$$

The subsequent yield state can be obtained from Equation (1) as follows:

$$
\begin{gathered}
d f=\frac{\partial f}{\partial \sigma_{i j}} d \sigma_{i j}-\frac{2}{3} \bar{\sigma} \frac{\partial \bar{C}}{\partial \overline{\varepsilon^{P}}} d \overline{\varepsilon^{P}}=0 \\
\text { Among them } \frac{\partial f}{\partial \sigma_{i j}}=\partial_{i j}^{\prime}
\end{gathered}
$$

From Equation (5), the relationship between plastic strain increment and stress increment can be obtained as follows:

$$
d \overline{\varepsilon^{p}}=\sqrt{\frac{2}{3} d \varepsilon_{i j}^{p} d \varepsilon_{i j}^{p}}=\frac{2}{3} \lambda \sqrt{\frac{3}{2} \sigma_{i j}^{\prime} \sigma_{i j}^{\prime}}=\frac{2}{3} \lambda \bar{\sigma}
$$

Substituting formulas (4), (7) and (8) into (6), the relationship is as follows:

$$
\sigma_{i j}^{\prime} \mathrm{d} \sigma_{i j}-\left(\frac{2}{3} \bar{\sigma}\right)^{2} H^{\prime} \lambda=0
$$

Substituting formulas (5) and (7) into (3), the relationship is as follows:

$$
d \sigma_{i j}=D\left(d \varepsilon_{i j}-\lambda \partial \sigma_{i j}^{\prime}\right)
$$

Substituting formula (10) into formula (9), the relationship is as follows:

$$
\lambda=\frac{\sigma_{i j}^{\prime} D d \varepsilon_{i j}}{\sigma_{i j}^{\prime} D \sigma_{i j}^{\prime}+\left(\frac{2}{3} \bar{\sigma}\right)^{2} H^{\prime}}
$$

Substituting the above equation into Equation (10), the relationship between the rim elastic-plastic stress increment and strain increment can be obtained as follows:

$$
d \sigma_{i j}=\left[D-\frac{\sigma_{i j}^{\prime} D d \varepsilon_{i j}}{\sigma_{i j}^{\prime} D \sigma_{i j}^{\prime}+\left(\frac{2}{3} \bar{\sigma}\right)^{2} H^{\prime}}\right] d \varepsilon_{i j}
$$

\subsection{The Rim Finite Element Solution Equation}

In finite element analysis, isoparametric elements are used to discretize the solution domain, and the displacement of the element coordinates is expressed by node interpolation: 


$$
\begin{gathered}
{ }^{0} x_{i}=\sum_{k=1}^{n} N_{k}{ }^{0} x_{i}^{k},{ }^{t} x_{i}=\sum_{k=1}^{n} N_{k}{ }^{t} x_{i}^{k},{ }^{t+\Delta t} x_{i}=\sum_{k=1}^{n} N_{k}{ }^{t+\Delta t} x_{i}^{k} \quad(i=1,2,3, \cdots) \\
{ }^{t} u_{i}=\sum_{k=1}^{n} N_{k}{ }^{t} u_{i}^{k}, \quad u_{i}=\sum_{k=1}^{n} N_{k} u_{i}^{k} \quad(i=1,2,3, \cdots)
\end{gathered}
$$

where, ${ }^{t} X_{i}^{k}$ is the coordinate component of node $k$ in the $i$ direction at time $t$, ${ }^{t} u_{i}^{k}$ is the displacement component of node $k$ in the $i$ direction at time $t, N_{k}$ is the shape function associated with node $k$, and $N$ is the number of nodes for unit interpolation.

The Piola Kirchhoff stress increment is related to the Green strain increment by the constitutive tensor, and the nonlinear equation described by T. L. can be obtained, Combining Equations (14) and (15) to calculate the displacement derivatives in the integral formulas of the full Lagrangian equation, the finite element matrix form of T. L. scheme is derived as follows [10]:

$$
\begin{aligned}
& \left({ }_{0}^{t}\left[K_{L}\right]+{ }_{0}^{t}\left[K_{N L}\right]\right)\{U\}={ }^{t+\Delta t}\{Q\}-{ }_{0}^{t}\{F\} \\
& \left({ }_{0}^{t}\left[K_{L}\right]+{ }_{0}^{t}\left[K_{N L}\right]\right)\{U\}={ }^{t+\Delta t}\{Q\}-{ }_{0}^{t}\{F\}
\end{aligned}
$$

where, ${ }^{t+\Delta t}\{Q\}$ is the node load vector; $\{U\}$ is the node displacement increment vector; ${ }_{0}^{t}\left[K_{L}\right],{ }_{0}^{t}\left[K_{N L}\right]$ and ${ }_{0}^{t}\{F\}$ respectively are $\int_{0_{V}}{ }_{0} D_{i j r s} 0 e_{r s} \delta_{0} e_{i j}{ }^{0} \mathrm{~d} V$, $\int_{0_{V}}{ }_{0}^{t} S_{i j} \delta_{0} \eta_{i j}{ }^{0} \mathrm{~d} V$ and $\int_{0_{V}}{ }_{0}^{t} S_{i j} \delta_{0} e_{i j}{ }^{0} \mathrm{~d} V$ points integration, The expression is as follows:

$$
\begin{gathered}
{ }_{0}^{t}\left[K_{L}\right]=\sum_{e} \int_{0_{V}}{ }_{0}^{t} B_{L}^{T}{ }_{0} D_{0}^{t} B_{L}{ }^{0} \mathrm{~d} V \\
{ }_{0}^{t}\left[K_{N L}\right]=\sum_{e} \int_{0_{V}}{ }_{0}^{t} B_{N L}^{T}{ }_{0}^{t} S_{0}^{t} B_{N L}{ }^{0} \mathrm{~d} V \\
{ }_{0}^{t}[F]=\sum_{e} \int_{0_{V}}{ }_{0}^{t} B_{L}^{T}{ }_{0}^{t} \hat{S}^{0} \mathrm{~d} V
\end{gathered}
$$

where, ${ }_{0}^{t} B_{L},{ }_{0}^{t} B_{N L}$ and ${ }_{0}^{t} B_{L}$ are the conversion matrices of linear strain, nonlinear strain, and displacement, respectively, ${ }_{0} D$ are the incremental material characteristic matrix, ${ }_{0}^{t} S$ and ${ }_{0}^{t} \hat{S}$ are the matrix formed by Piola-Kirchhoff stress.

\section{Simulation Modeling of Rim Rolling}

\subsection{Rolling Process}

Roll forming is an advanced cold forging process, The forming process is complex, including rounding, welding and slagging, flaring, one-pass rolling, two-pass rolling, three-pass rolling, expansion finishing and Inflatable door holes and other processes [11]. However, the deformation of the rim mainly occurred in the process of three-pass rolling. In order to control the forming quality of rim, the rim three-pass rolling process of rim was simulated.

\subsection{Finite Element Model of Wheel Rim}

According to the rim rolling forming principle, the rim three pass rolling model 
is shown in Figure 1.

The function of the first roll forming is the pre-forming of the rim, which mainly rolls out the transition shape of the deep groove and rounded corners of the rim, and the flared parts on both sides are not deformed, the second pass of roll forming is mainly to shape the groove bottom and fillet part, and pre-shape the flange part at the same time, the third pass of roll forming accurately forms the rim so that its shape and size meet the standard requirements [12]. The schematic diagrams of each pass of roll forming are shown in Figure 2.

\subsection{Model Parameter Setting}

In order to ensure the accuracy of simulation and obtain the accurate mechanical properties parameters of the rim material, the tensile test machine was used

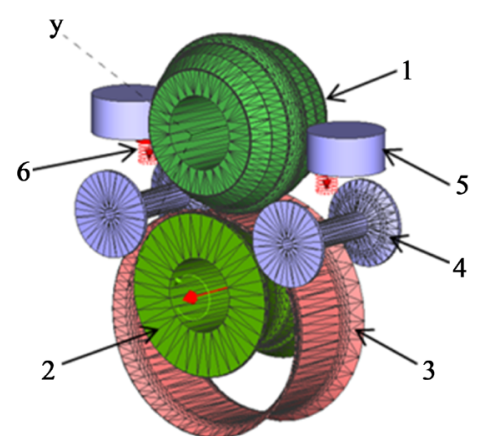

(a)

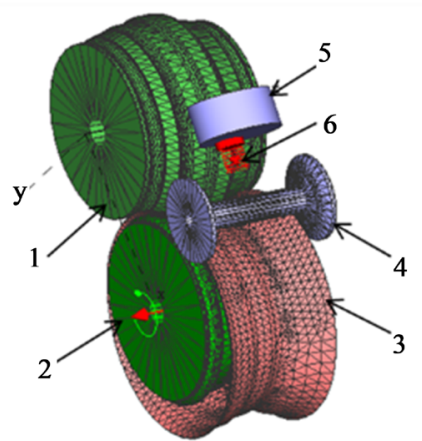

(b)



(c)

Figure 1. Finite element model: (a) first rolling model; (b) second rolling model; (c) third rolling model. (1. Upper roller die 2. Lower roller die 3. Blank 4. Guide wheel 5. Stopper 6. Spring).

(a)

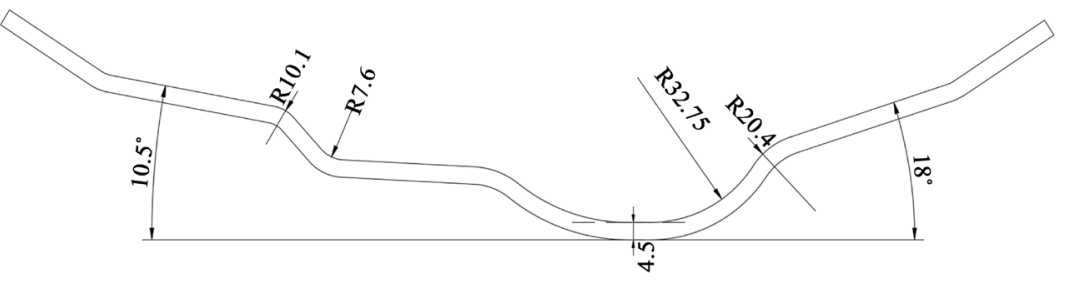

(b)

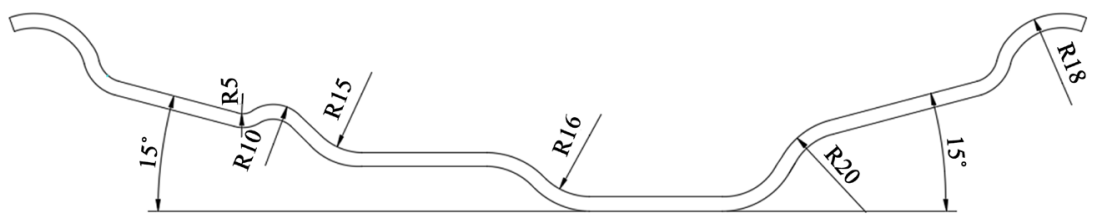

(c)

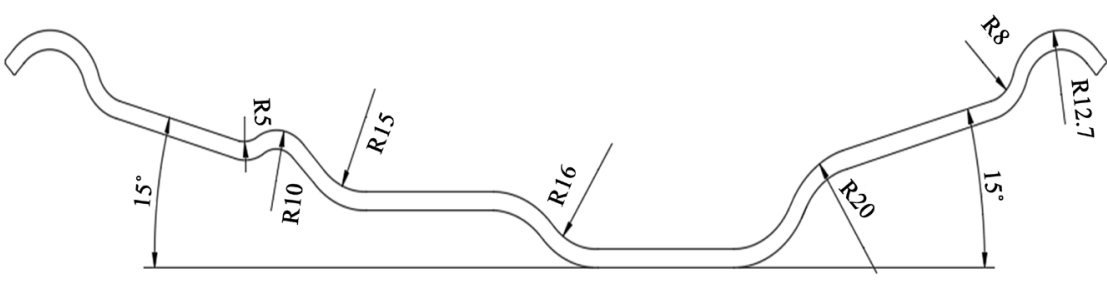

Figure 2. Rolling forming diagram of each pass: (a) first roll forming schematic diagram; (b) schematic diagram of second roll forming; (c) schematic diagram of third roll forming. 
to conduct tensile tests on 3 specimens of the same type. Figure 3 shows the stress-strain relationship obtained during the test, and Table 1 shows the material performance parameters obtained after the tensile test.

In the rolling process, almost no deformation occurs in the mold, which is defined as analytic rigid body [13]. As the amount of deformation of billet is large, solid unit type should be adopted, hexahedral mesh should be divided, unit size is $5 \mathrm{~mm}$, and unit number is 68,496 .

In the actual processing, the regulating wheel is connected to the cylinder, and the blank is pressed by air pressure [14]. In the simulation, the effect of air pressure is replaced by the die spring, so that the regulating wheel and the flange are inflexible contacts, and the boundary conditions similar to the actual effect are achieved, as shown in Figure 4.

The rolling time includes feed forming time and progressive forming time, which are related to feed quantity, feed speed and blank rotation speed. The time step is calculated by

$$
\begin{gathered}
t=t_{1}+t_{2} \\
t_{1}=\frac{d}{v}
\end{gathered}
$$

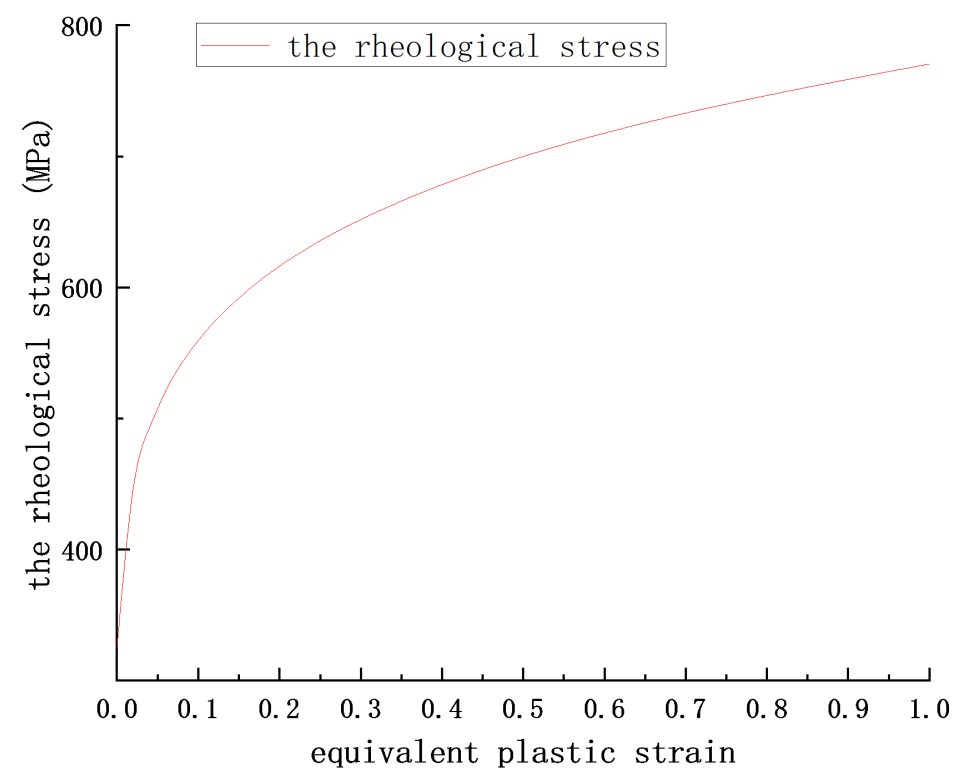

Figure 3. Stress-strain curve.

Table 1. Material parameters of an alloy steel.

\begin{tabular}{cccccccc}
\hline specimen & $\begin{array}{c}\text { Density } \\
\left(\mathrm{kg} / \mathrm{m}^{3}\right)\end{array}$ & $\begin{array}{c}\text { Elastic } \\
\text { Modulus } \\
(\mathrm{GPa})\end{array}$ & $\begin{array}{c}\text { Poisson's } \\
\text { ratio }\end{array}$ & $\begin{array}{c}\text { tensile } \\
\text { strength } \\
(\mathrm{MPa})\end{array}$ & $\begin{array}{c}\text { Plastic } \\
\text { extension } \\
\text { strength }(\mathrm{MPa})\end{array}$ & $\begin{array}{c}\text { Elongation } \\
(\%)\end{array}$ & $\begin{array}{c}\text { Yield } \\
\text { Strength } \\
(\mathrm{MPa})\end{array}$ \\
\hline 1 & 7830 & 210 & 0.3 & 468.46 & 321.92 & 32.88 & 468.13 \\
2 & 7830 & 210 & 0.3 & 469.82 & 317.68 & 32.02 & 469.28 \\
3 & 7830 & 210 & 0.3 & 468.08 & 324.53 & 32.48 & 467.87 \\
\hline
\end{tabular}






Figure 4. Guide wheel-flange boundary contac.

$$
t_{2}=\frac{2 n \pi}{w}
$$

where, $t$ is the time step, $t_{1}$ is the feed forming time, $t_{2}$ is the progressive forming time, $v$ is the feed velocity, $d$ is the feed quantity, $n$ is the number of turns of the progressive forming workpiece, $n$ is 1 .

The billet rotation speed $(w)$ is calculated based on the equal linear velocity of the rolling contact point.

$$
v_{1}=2 \pi r_{1} w_{1}=2 \pi r_{2} w_{2}
$$

where, $V_{1}$ is the linear velocity of the contact point, $r_{1}$ is the roll-down radius, $w_{1}$ is the roll-down speed, $r_{2}$ is the blank radius, and $w_{2}$ is the blank speed.

\section{Simulation Result Analysis}

\subsection{Analysis of the Influence of Process Parameters on Forming Quality}

The main process parameters that affect the quality of rim roll forming include friction coefficient, feed speed and wheel speed. In actual production, the process parameters are mainly selected by the researcher's experience and cannot ensure the optimal combination of parameters. In order to study the relationship between process parameters and forming quality, a single parameter experiment method was used to simulate the rim.

1) The influence of friction on the forming quality

In rolling processing, the workpiece and the mold are rotated by friction, but due to the influence of lubrication conditions and the wear of the mold surface, it is difficult to determine the relationship between the friction and the workpiece. Combined with practical experience, keep the feed speed $21.89 \mathrm{~mm} / \mathrm{s}$ and the speed $200 \mathrm{r} / \mathrm{min}$ unchanged, and explore the influence of the friction coefficient on the forming quality when the friction coefficient is $0.2,0.3$ and 0.4 . The results in Figure 5(a) show that the thickness change trend of each measuring point in different friction coefficients is the same, that is, rounded corners and the flange area has a large thinning, while the other areas have relatively small thinning. When $f=0.2$, rounded corners and flange thinning are relatively large, which is not conducive to the processing and forming of the workpiece. As the 



Figure 5. Relationship between friction and forming quality: (a) the thickness change curve of the measuring point under different friction coefficients; (b) relationship curve between maximum thinning rate and friction coefficient.
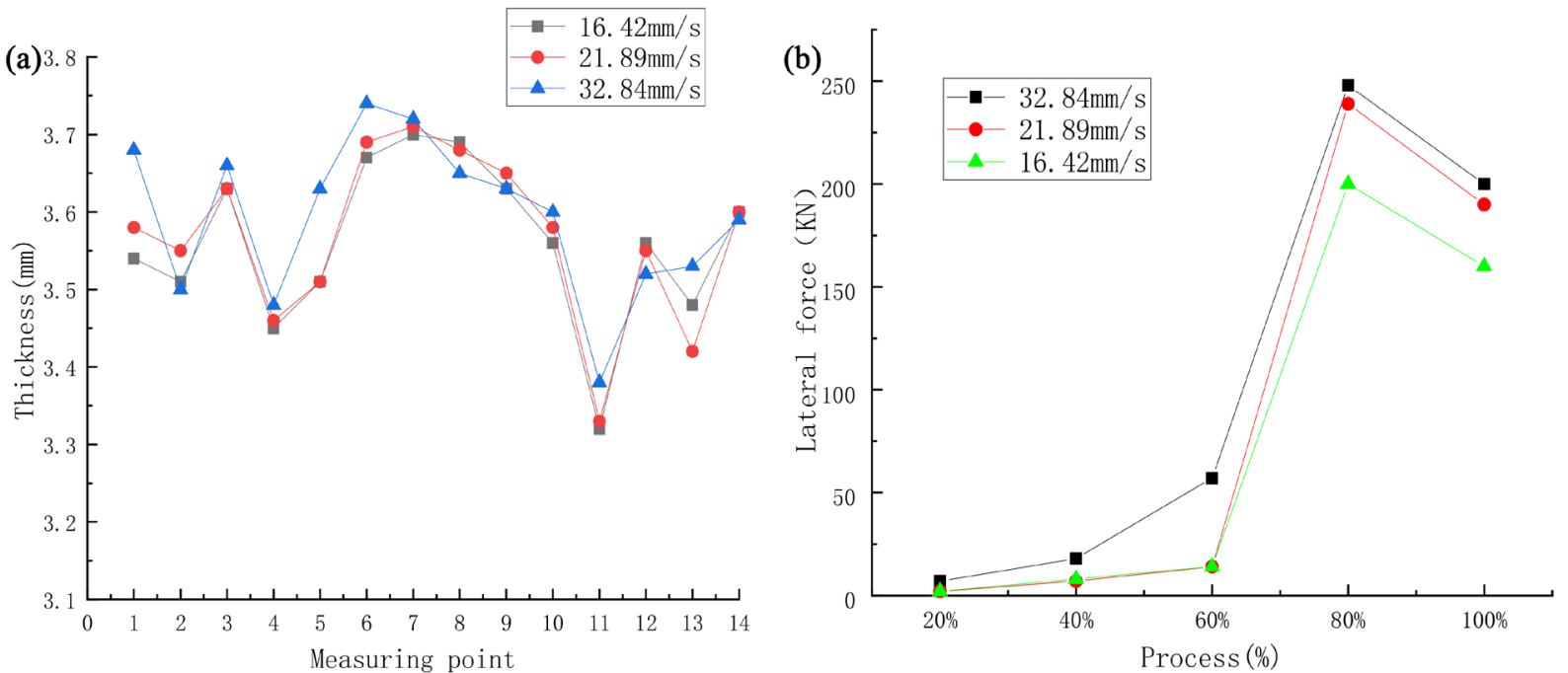

Figure 6. Relationship between feed rate and forming quality: (a) measuring point-thickness change curve at different feed speeds; (b) lateral force curve at different feed speeds. 
thickness of the workpiece is only $3.32 \mathrm{~mm}$. As the feed rate increases, the thickness of the measuring point increases and the forming quality of the workpiece tends to be better, so it can be increased appropriately feed rate. However, in actual processing, the feed speed of the mold is too fast, which will cause the workpiece to produce lateral force and the workpiece will shift. As shown in Figure 6(b) the lateral force curve at different feed speeds, as the feed speed becomes larger, the lateral force also becomes larger, which is more likely to cause the workpiece to shift. Comprehensively considering its influence on the forming thickness and lateral force, multiple simulations and adjustments, a feed speed of $21.89 \mathrm{~mm} / \mathrm{s}$ can obtain an ideal workpiece quality.

3) The influence of roller speed on forming quality

The speed ratio of the roller is matched inversely according to the diameter of the roller [15], which ensures that the linear velocity of the roller and the workpiece are equal on the contact surface, and reduces the forming defects of the workpiece. With the friction coefficient of 0.3 and the feed speed of $21.89 \mathrm{~mm} / \mathrm{s}$ unchanged, the influence of the rotating speed of the upper roller die on the forming quality of the workpiece at $150 \mathrm{r} / \mathrm{min}, 200 \mathrm{r} / \mathrm{min}$ and $250 \mathrm{r} / \mathrm{min}$ was studied. Figure 7(a) shows the thickness change curve of measuring points at different rotating speeds. It is found in the figure that with the increase of rotating speed, the thickness of groove, flange and rounded corners in a roll decreases to different degrees, and the thinning of rounded corners is the most serious. In order to ensure the safety of the wheels, the speed of the rollers should be appropriately reduced to control the thinning of the rim. However, if the speed is too small, it will cause uneven forming of the rim, as shown in Figure 7 (b) for the rim strain curve under the same section. Comparative analysis found that the deformation shapes of the two sections of the rim were obviously different when the rotating speed was $150 \mathrm{r} / \mathrm{min}$. In particular, the upper section had small strain and deformation, which could not meet the forming requirements. However, the workpiece with uniform thickness and better quality could be obtained when the rotating speed was about $200 \mathrm{r} / \mathrm{min}$.

\subsection{Analysis of Simulation Results under Parameter Optimization Conditions}

Simufact Forming software is used to perform finite element simulation on the rim. In the simulation, the feed distance is the translational distance of the roller, and the analysis results of the speed, feed speed, time step and feed distance are shown in Table 2.

The analysis cloud diagram of the rolling stress and strain of each pass is shown in Figure 8. The equivalent stress at the end of the rolling of a rolled workpiece reaches $648.92 \mathrm{MPa}$, and the equivalent stress in the groove and the rounded area is larger than that in other areas, and the stress value in the area near the flange is smaller. The main reason is that the groove area first comes into contact with the flange of the upper roller die during rolling, which produces a larger compressive stress during the feed stroke. The equivalent strain of the 


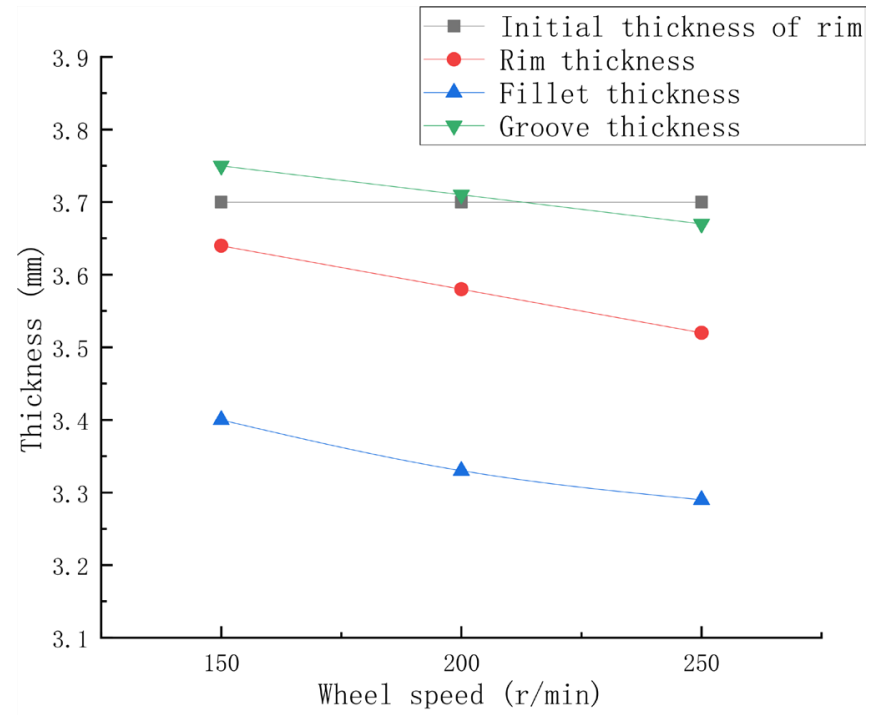

(a)

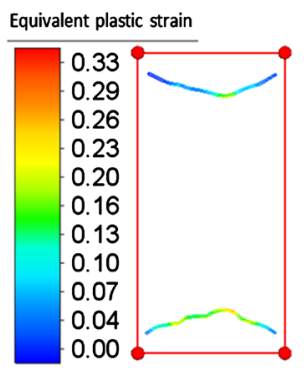

(bi)

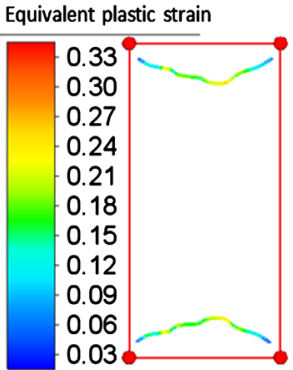

(b2)

Figure 7. Strain curve of the same section rim: (a) the thickness change of the measuring point at different speeds; $\left(b_{1}\right) 150 \mathrm{r} / \mathrm{min}$ rim strain curve; $\left(b_{2}\right) 200 \mathrm{r} / \mathrm{min}$ rim strain curve.

Table 2. The speed, feed speed, time step and feed distance of each pass rolling die.

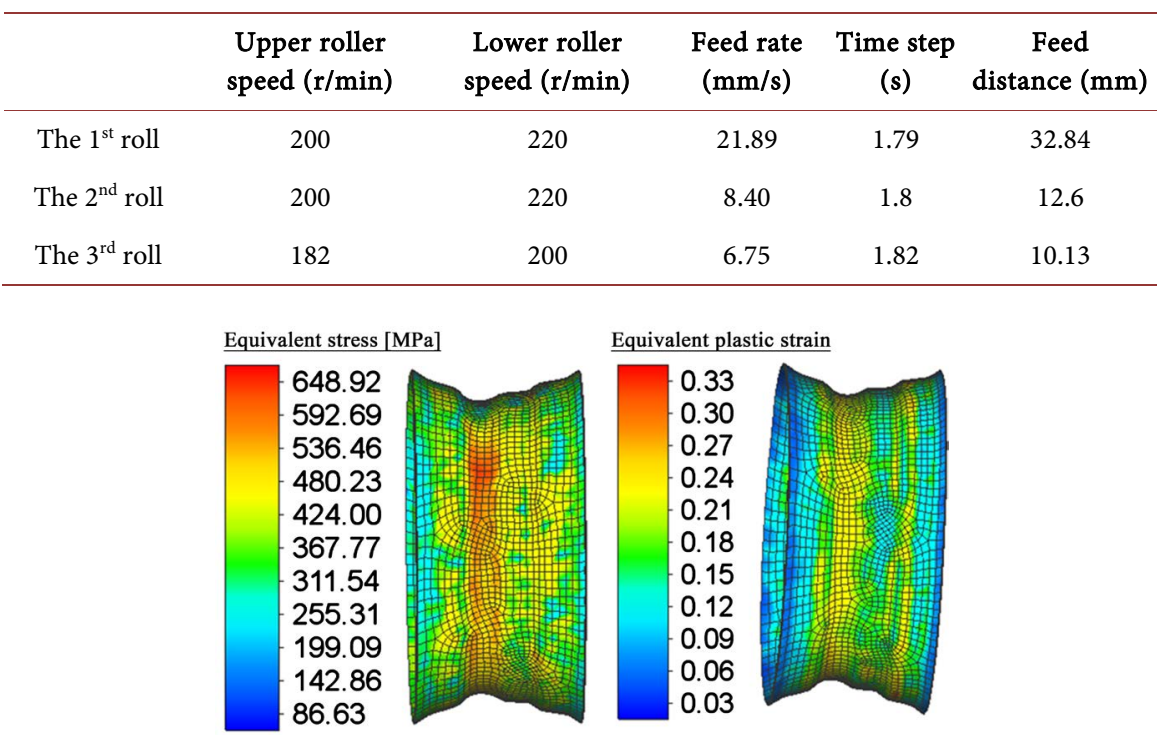

(a)

(b)

Figure 8. First rolling stress and strain cloud diagram: (a) equivalent stress cloud diagram; (b) equivalent strain cloud diagram. 
workpiece reaches 0.33 , the equivalent strain value of the groove and the rounded area is larger, and the strain value of the flange area is smaller, indicating that the plastic deformation occurs in the groove area is larger.

The second pass roll forming shape, mainly preform the flange area, and further shape the groove and rounded corners. Figure 9 shows the equivalent stress cloud diagram and equivalent strain cloud diagram of the second rolling. The equivalent stress at the end of the blank rolling reaches $714.84 \mathrm{MPa}$, and the maximum equivalent stress appears in the flange part, and the groove and rounded also produce large stress; The maximum equivalent strain is 0.47 , which also occurs at the flange, indicating that the material deformation at this place is also large.

The third pass rolls mainly shape the wheel flange accurately, and makes the groove fillet size meet the requirements of the workpiece. Figure 10 shows the equivalent stress cloud diagram and equivalent strain cloud diagram of the third pass rolls. The stress value at the end of rolling reaches $726.69 \mathrm{MPa}$, the strain value reaches 0.64 , and the large stress and large strain are mainly concentrated at the flange and groove fillet. Since the basic shape of the rim has been formed after the first and second rolls, the third pass rolls are mainly refined, with small deformation and more even stress distribution.

In order to analyze in detail the rolling simulation process of each pass of the rim, the particle tracking technology is introduced into the rolling results to

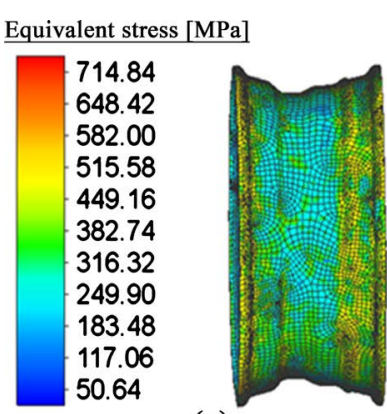

(a)

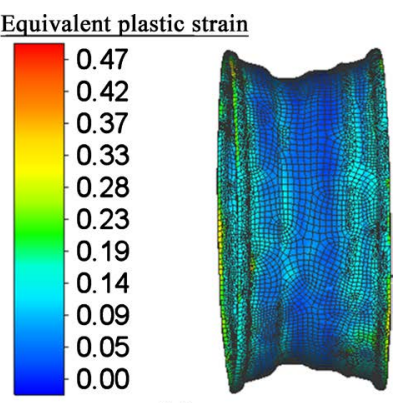

(b)

Figure 9. Second rolling stress and strain cloud diagram: (a) equivalent stress cloud diagram; (b) equivalent strain cloud diagram.

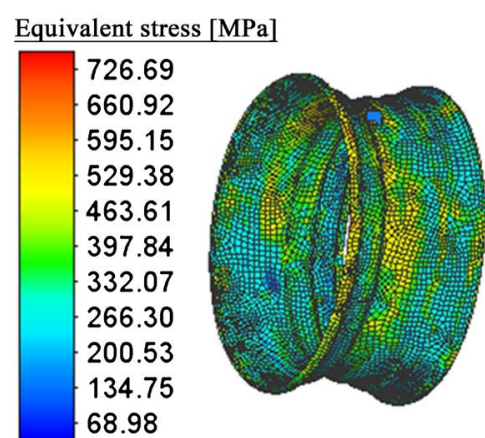

(a)

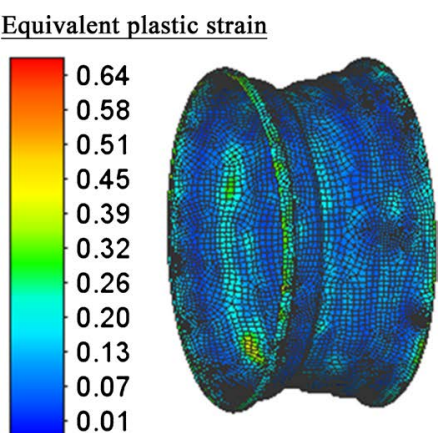

(b)

Figure 10. Third rolling stress and strain cloud diagram: (a) equivalent stress cloud diagram; (b) equivalent strain cloud diagram. 
track the stress change process of the workpiece at each time step. Figure 11. shows the variation curve of equivalent stress with time step obtained by a rolling equivalent stress nephogram tracked by particle. Within $0-1.5 \mathrm{~s}$, as the time step increases, the equivalent stress of the workpiece continues to increase. This stage is mainly the feeding stage of the workpiece. The distance between the upper and lower molds gradually decreases, and the workpiece is squeezed and deformed, resulting in greater stress. After $1.5 \mathrm{~s}$, it enters the progressive forming stage, the distance between the upper and lower molds remains unchanged, the workpiece is uniformly formed, and the equivalent stress tends to stabilize.

Figure 12 shows the curve of the equivalent stress of the second rolling over time. In $0-1.5 \mathrm{~s}$, the groove first contacts the roller and deforms, and the equivalent stress increases with the increase of the time step; the equivalent stress reaches the maximum at $1.5 \mathrm{~s}$ and the feed stroke ends; after $1.5 \mathrm{~s}$, it enters the gradual forming stage, the equivalent stress remains in a larger value area, and the workpiece is uniformly formed with the rotation of the roller.

The relationship curve between third rolling equivalent stress and forming time is shown in Figure 13. In the feed forming stage, the equivalent stress of 0 $1 \mathrm{~s}$ increases rapidly. Combined with the dynamic simulation analysis of the equivalent stress, it is found that the roller only contacts the flange during this process, indicating that the flange has large stress at this time step; $1-1.5 \mathrm{~s}$ roller contacts with the groove, and the groove corner starts to be formed precisely under the pressure, and the stress value of the flange keeps increasing; after $1.5 \mathrm{~s}$, it enters the progressive forming stage, the stress tends to be stable, and the groove rounded corners and flanges complete accurate forming.

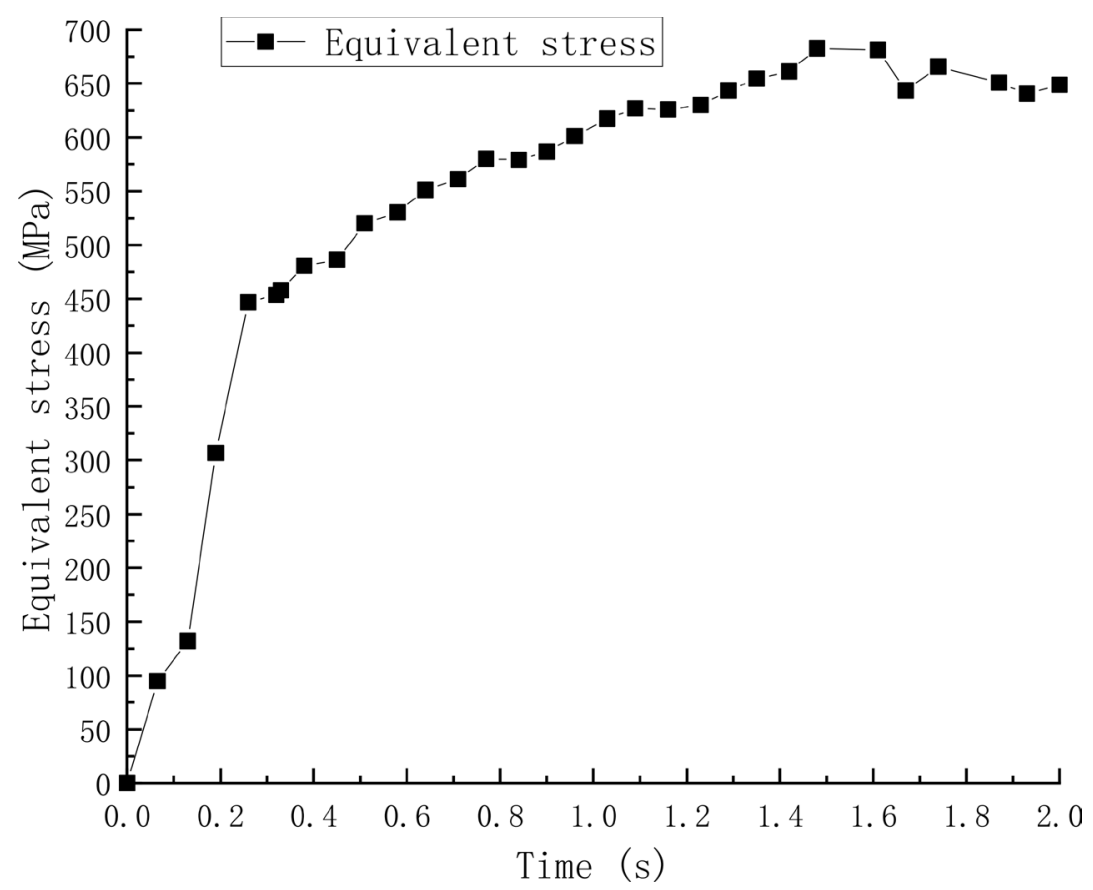

Figure 11. A roll equivalent stress curve. 


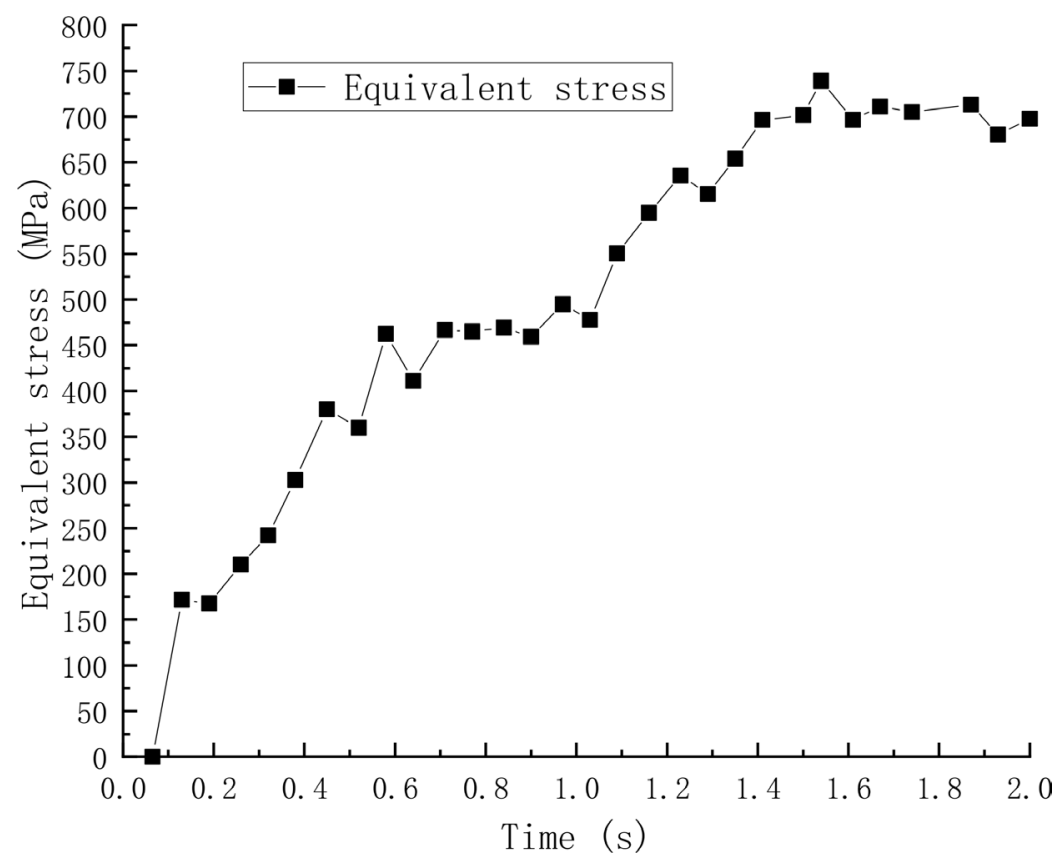

Figure 12. Second rolling equivalent stress curve.

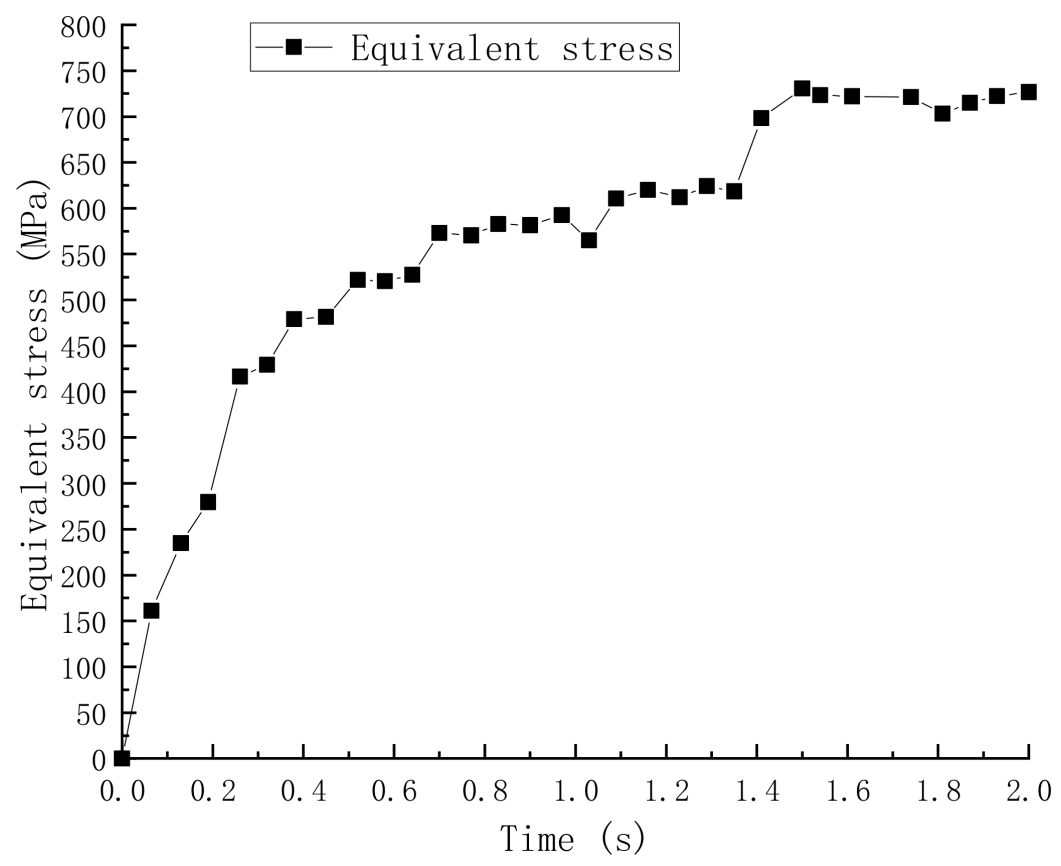

Figure 13. Third rolling equivalent stress curve.

\section{Roll Test Verification}

In order to verify the correctness of the simulated rim forming, the actual production workpiece and the simulated formed workpiece were compared and analyzed in thickness. The rim rolling process is shown in Figure 14. According to the actual rolling equipment 14 (a), the rim rolling forming device $14(\mathrm{~b})$ is simplified, which is mainly composed of up roll, down roll, blank, guide wheel, air cylinder and main shaft [16]. 




(a)

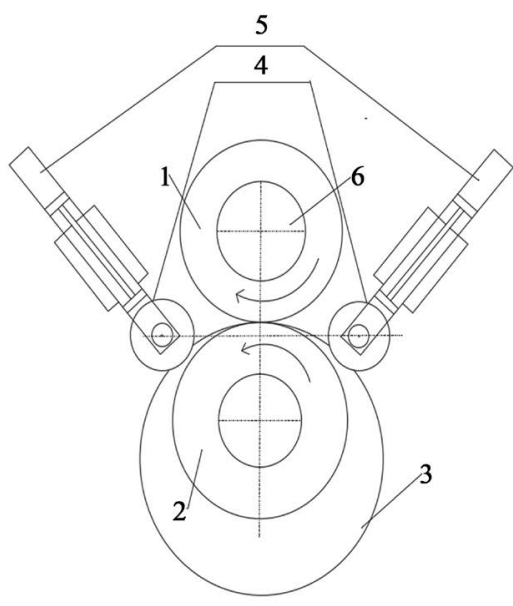

(b)

Figure 14. Rim rolling equipment: (a) rolling equipment; (b) roll forming simplified device. (1. Upper roller 2. Lower roller 3. Blank 4. Guide wheel 5. Air cylinder 6. Spindle).

(a)

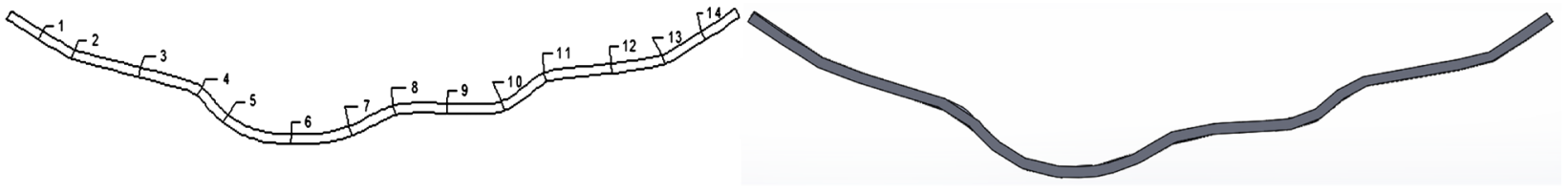

(b)


(c)
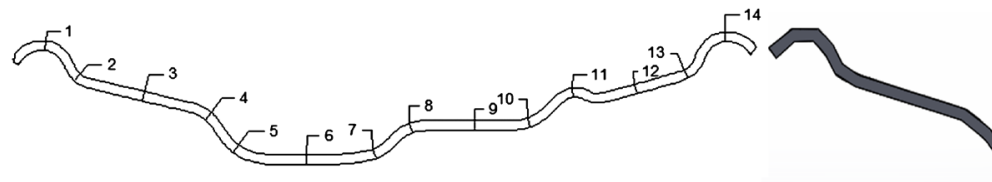

Figure 15. Actual and simulated cross-sectional shape of each pass: (a) first rolling; (b) second rolling; (c) third rolling.

Through the rim rolling process, each pass roll forming workpiece is obtained. Figure 15 shows the cross-sectional shape of the actual roll forming rim and the simulated cross-sectional shape. The actual cross-sectional shape of the workpiece is obtained by computer vision measurement. The thickness of the measuring point is mainly selected from the areas that are more sensitive to thickness changes during the rolling process (rounded corners, grooves and flange). Figure 16 shows the comparison curve between actual measured thickness and simulated thickness.

It can be found from Figure 15 that the simulated cross-sectional shape is basically the same as the actual processed cross-sectional shape. The simulation data curve of each pass in Figure 16. is basically consistent with the actual measurement curve, which proves the feasibility of simulation. Among them, the largest thinning area of the roll thickness occurred at the rounded corner, which was subjected to large tensile and compressive stresses, and the deformation was 


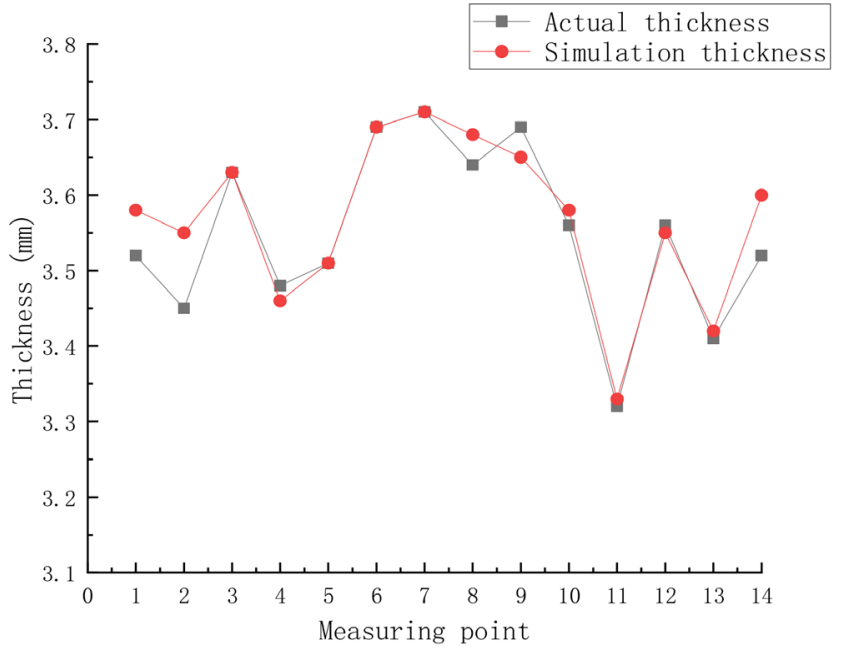

(a)

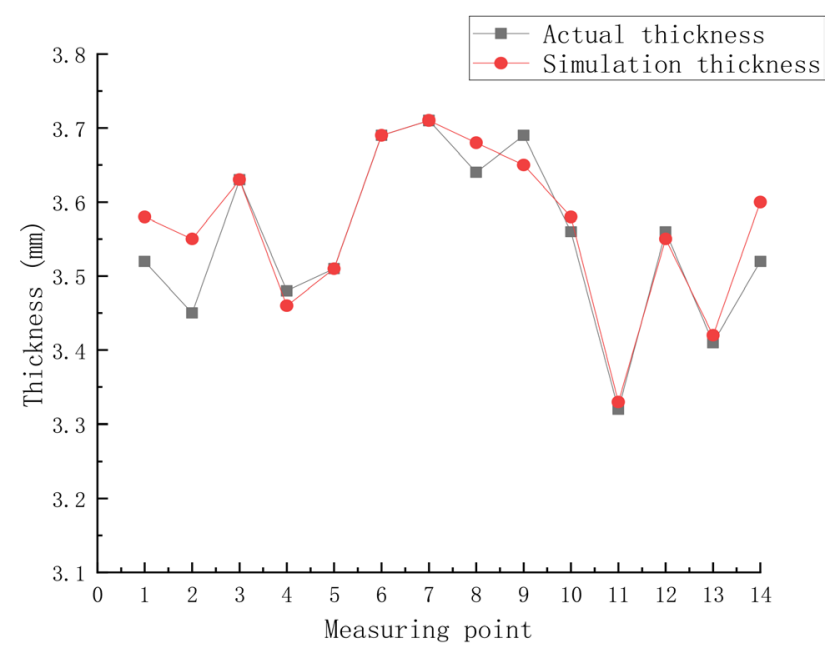

(b)

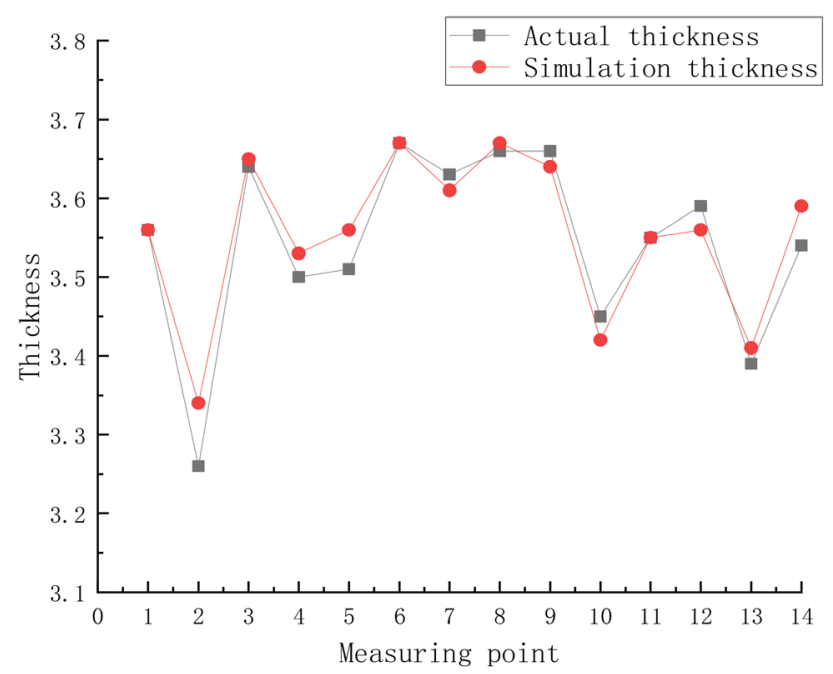

(c)

Figure 16. Comparison curve of each pass experiment-simulation thickness: (a) first rolling thickness comparison curve; (b) second rolling thickness comparison curve; (c) third rolling thickness comparison curve.

large, and the thinning rate reached $10 \%$, the flange is subjected to little compressive stress, and under the action of tensile stress, the material flows to the fillet to compensate for excessive thinning of fillet; The largest thickness thinning area of the second roll occurs at the wheel rim, mainly because of the preforming of the wheel rim, the stress is large, the deformation is large, and there is no material supplement in this area, the thinning rate reaches $10.8 \%$, and the thinning rate of other positions is small; After three-roll forming, the thickness distribution is relatively uniform, and the largest thinning area occurs at the rounded corner, and the thinning rate is about $9.7 \%$.

\section{Conclusions}

1) The increase of the friction coefficient is beneficial to the forming of the 
workpiece, but after the friction coefficient is increased to 0.3 , the effect on the forming quality is not obvious. The increase of the feed speed will increase the thickness of the measuring point, which is conducive to forming, but if the feed speed is too high, the lateral force will increase, which will easily cause the workpiece to shift. The reduction of the speed is beneficial to control the thinning of the rim, but if the speed is too small, the formation of the rim will be uneven.

2) The simulation results show that first rolling rounded corner and groove produce greater stress and strain. Second rolling pre-formed flange, where the stress and strain are both large, and the maximum equivalent stress appears at the flange, and the groove and rounded corner also produce large stress. Third rolling rim is accurately formed, the stress distribution is more uniform, and the fillet deformation is relatively small.

3) Comparative analysis of experimental and simulation results. The simulated forming thickness is basically consistent with the experimentally measured thickness, which proves the feasibility of simulation. The design optimization of new products can be carried out on this basis, which has certain reference value for the production and processing of enterprises.

\section{Authors Contributions}

Conceptualization, W.L. and M.P.; methodology, W.L.; software, S.L.; validation, W.L., M.P. and S.L.; data curation, M.C.; writing-review and editing, W.L.; writing-review and editing, M.P. and M.C.; supervision, M.C.; All authors have read and agreed to the published version of the manuscript.

\section{Funding}

The research was supported by the natural science foundation of Zhejiang Province with the grant number (LQY19E050001), and the school enterprise cooperation project with the grant number (20193300102049).

\section{Conflicts of Interest}

The authors declare no conflicts of interest regarding the publication of this paper.

\section{References}

[1] Pan, Y.T., Ma, X.M. and Ma, Y. (2009) Research on Lightweight Technology of Wheel Hub of Crawler Self-Propelled Gun. Journal of Gun Launch and Control, $41-44,49$.

[2] Gao, M.D., Wang, Q.Y., Li, L.M., et al. (2020) Energy-Economizing Optimization of Magnesium Alloy Hot Stamping Process. Processes, 8, 186-203. https://doi.org/10.3390/pr8020186

[3] Deng, R., Shi, L., Yu, Z.Q., et al. (2010) Numerical Simulation Technology of Rim Rolling Forming. Mechanical Design and Research, 26, 80-83.

[4] Wang, H.L., Yu, Z.Q. and Li, S.H. (2009) Research on Simulation and Forming Process of Rim Rolling Process. Shanghai Jiao Tong University, Shanghai. 
[5] Li, Y.H., Fan, T. and Liang, X.J. (2012) Finite Element Simulation Analysis of Cold Rolling Process for Stainless Steel Tube. Applied Mechanics and Materials, 182-183 1494-1498. https://doi.org/10.4028/www.scientific.net/AMM.182-183.1494

[6] Li, D.Y., Jiang, J.M., Peng, Y.H., et al. (2007) Simulation and Parameter Optimization of Roll Forming Process. Journal of System Simulation, No. 4, 893-896.

[7] Tao, H.W., Zhao, J., Pang, J.M., et al. (2017) Influence of Roller Rolling Speed on Asymmetric Rim Forming. Mechanical Design and Manufacturing, 90-93.

[8] Liu, Z.W., Dong, F.F. and Li, L.X. (2015) Optimization of Process Parameters of Large Diameter Thin Steel Tube for Automobile Bumper. Automotive Engineering, 37, 853-860.

[9] Ou, H. and Armstrong, C.G. (2006) Evaluating the Effect of Press and Die Elasticity in Forging of Aerofoil Sections Using Finite Element Simulation. Finite Elements in Analysis and Design, 42, 856-867. https://doi.org/10.1016/j.finel.2006.01.006

[10] Wang, X.C. (2003) Finite Element Method. Tsinghua University Press, Beijing.

[11] Gang, F., Gao, W.R. and Zhag, X.G. (2015) Finite Element Simulation and Experiment Verification of Rolling Forming for the Truck Wheel Rim. International Journal of Precision Engineering and Manufacturing, 16, 1509-1515. https://doi.org/10.1007/s12541-015-0200-4

[12] Bi, D.S., Guang, Y., Liang, C., et al. (2011) Numerical Simulation Analysis of Spinning Forming Process of Tubeless Steel Wheel on Technical Parameters. Advanced Materials Research, 189-193, 2322-2328.

https://doi.org/10.4028/www.scientific.net/AMR.189-193.2322

[13] Wang, Y., Hu, J.F., Xu, G.H., et al. (2016) Numerical Simulation and Experimental Verification of Three Roll Asymmetric Roll Forming. China Mechanical Engineering, 27, 2085-2090.

[14] Lu, P., Zhang, Y.K. and Ma, F. (2015) Finite Element Analysis on Multi-Step Rolling Process and Controlling Quality Defect for Steel Wheel Rim. Advances in Mechanical Engineering, 7, 1-11.

[15] Chen, D.C., Lai, B.Y. and You, C.S. (2012) Finite Element Analysis of Rim Ring Rolling Forming of Bicycle Aluminum Alloy. Advanced Materials Research, 445, 231-236. https://doi.org/10.4028/www.scientific.net/AMR.445.231

[16] Zhang, L.H. (2013) Numerical Simulation Study on Rolling Process of Steel Wheel Rim. Shandong University, Jinan. 